\title{
HTCC as a Polymeric Inhibitor of SARS-CoV-2 and MERS-CoV
}

\author{
Aleksandra Milewska, ${ }^{a, b}$ Ying Chi,c Artur Szczepanski, a,b Emilia Barreto-Duran, a Agnieszka Dabrowska, a,b Pawel Botwina, ${ }^{a, b}$ \\ Magdalena Obloza, ${ }^{d}$ Kevin Liu, e Dan Liu, ${ }^{e}$ Xiling Guo, ${ }^{c}$ Yiyue Ge, ${ }^{c}$ Jingxin Li, ${ }^{c}$ Lunbiao Cui, ${ }^{c}$ Marek Ochman, ${ }^{f}$ Maciej Urlik,

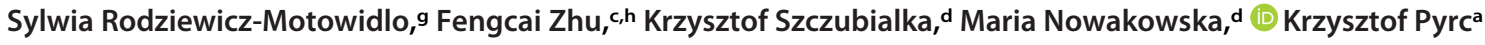

\begin{abstract}
airogenetics Laboratory of Virology, Malopolska Centre of Biotechnology, Jagiellonian University, Krakow, Poland
bMicrobiology Department, Faculty of Biochemistry, Biophysics and Biotechnology, Jagiellonian University, Krakow, Poland

‘NHC Key Lab of Enteric Pathogenic Microbiology, Jiangsu Provincial Centre for Disease Control \& Prevention, Nanjing, Jiangsu, People's Republic of China

aDepartment of Physical Chemistry, Faculty of Chemistry, Jagiellonian University, Krakow, Poland

eNanjing Techboon Institute of Clinical Medicine, Nanjing, Jiangsu, People's Republic of China

fDepartment of Cardiac, Vascular and Endovascular Surgery and Transplantology, Silesian Centre for Heart Diseases, Medical University of Silesia in Katowice, Zabrze, Poland

gDepartment of Biomedical Chemistry, Faculty of Chemistry, University of Gdansk, Gdansk, Poland

hCentre for Global Health, Nanjing Medical University, Nanjing, Jiangsu, People's Republic of China
\end{abstract}

Fengcai Zhu, Krzysztof Szczubialka, Maria Nowakowska, and Krzysztof Pyrc are senior co-authors.

ABSTRACT Among seven coronaviruses that infect humans, three (severe acute respiratory syndrome coronavirus [SARS-CoV], Middle East respiratory syndrome coronavirus [MERS-CoV], and the newly identified severe acute respiratory syndrome coronavirus 2 [SARS-CoV-2]) are associated with a severe, life-threatening respiratory infection and multiorgan failure. We previously proposed that the cationically modified chitosan $\mathrm{N}$-(2-hydroxypropyl)-3-trimethylammonium chitosan chloride (HTCC) is a potent inhibitor of human coronavirus NL63 (HCoV-NL63). Next, we demonstrated the broad-spectrum antiviral activity of the compound, as it inhibited all low-pathogenicity human coronaviruses (HCoV-NL63, HCoV-229E, HCoV-OC43, and HCoV-HKU1). Here, using in vitro and ex vivo models of human airway epithelia, we show that HTCC effectively blocks MERS-CoV and SARS-CoV-2 infection. We also confirmed the mechanism of action for these two viruses, showing that the polymer blocks the virus entry into the host cell by interaction with the $S$ protein.

IMPORTANCE The beginning of 2020 brought us information about the novel coronavirus emerging in China. Rapid research resulted in the characterization of the pathogen, which appeared to be a member of the SARS-like cluster, commonly seen in bats. Despite the global and local efforts, the virus escaped the health care measures and rapidly spread in China and later globally, officially causing a pandemic and global crisis in March 2020. At present, different scenarios are being written to contain the virus, but the development of novel anticoronavirals for all highly pathogenic coronaviruses remains the major challenge. Here, we describe the antiviral activity of an HTCC compound, previously developed by us, which may be used as a potential inhibitor of currently circulating highly pathogenic coronaviruses-SARSCOV-2 and MERS-CoV.

KEYWORDS HTCC, MERS, SARS-CoV-2, chitosan, coronaviridae, coronavirus, entry, inhibitor, inhibition

oronaviruses mainly cause respiratory and enteric diseases in humans, other mam-

mals, and birds. However, some species can cause more-severe conditions such as hepatitis, peritonitis, or neurological disease. Seven coronaviruses infect humans, four of which (human coronavirus 229E [HCoV-229E], HCoV-NL63, HCoV-OC43, and HCoV-
Citation Milewska A, Chi Y, Szczepanski A, Barreto-Duran E, Dabrowska A, Botwina P, Obloza M, Liu K, Liu D, Guo X, Ge Y, Li J, Cui L, Ochman M, Urlik M, Rodziewicz-Motowidlo S, Zhu F, Szczubialka K, Nowakowska M, Pyrc K. 2021. HTCC as a polymeric inhibitor of SARSCoV-2 and MERS-CoV. J Virol 95:e01622-20. https://doi.org/10.1128/JVI.01622-20. Editor Tom Gallagher, Loyola University Chicago

Copyright $\odot 2021$ American Society for Microbiology. All Rights Reserved.

Address correspondence to Aleksandra Milewska, aleksandra.milewska@uj.edu.pl, or Krzysztof Pyrc, k.a.pyrc@uj.edu.pl.

Received 11 August 2020

Accepted 14 November 2020

Accepted manuscript posted online 20 November 2020

Published 28 January 2021 
HKU1) cause relatively mild upper and lower respiratory tract disease. Three other zoonotic coronaviruses - the severe acute respiratory syndrome coronaviruses (SARS-CoV and SARS-CoV-2) and the Middle East respiratory syndrome coronavirus (MERS-CoV)are associated with severe, life-threatening respiratory infections and multiorgan failure (1-7).

SARS-CoV-2 emerged in the Hubei province of China by the end of 2019 and caused an epidemic that was partially contained in China by March 2020 (8). However, the virus rapidly spread globally and caused the pandemic. SARS-CoV-2 is a betacoronavirus and belongs to a large cluster of SARS-like viruses in bats, classified in the Sarbecovirus subgenus. While bats are considered to be the original reservoir, it is believed that there is an intermediate host, and pangolins were suggested as such (9). The virus is associated with a respiratory illness that, in a proportion of cases, is severe. The mortality rate varies between locations but, at present, is estimated to reach $3 \%$ to $4 \%$ globally. The virus infects primarily ciliated cells and type II pneumocytes in human airways, hijacking angiotensin-converting enzyme 2 (ACE2) to enter the cell, similarly to SARSCoV and HCoV-NL63.

MERS-CoV is related to SARS-CoV-2 but, together with some bat viruses, forms a separate Merbecovirus subgenus. Bats are believed to serve as an original reservoir also in this case (10), but camels were identified as the intermediate host (11). The virus never fully crossed the species border, as the human-to-human transmission is limited, and the majority of cases are associated with animal-to-human transmission. The entry receptor for MERS-CoV is dipeptidyl peptidase 4 (DPP4) $(12,13)$. In humans, MERS-CoV causes a respiratory illness with severity ranging from asymptomatic to potentially fatal acute respiratory distress (14-16). To date, MERS-CoV infection was confirmed in 27 countries, with over 2,000 cases and a mortality rate of $\sim 35 \%$.

Currently, there are no vaccines or drugs with proven efficacy to treat coronavirus infection, and treatment is limited to supportive care. However, a range of therapeutics have been experimentally used in clinics to treat SARS-CoV-2-infected and MERS-CoVinfected patients, and their use is based on the knowledge obtained in previous years. The most promising drug candidates include broad-spectrum polymerase inhibitors (remdesivir) (17) and some repurposed drugs (e.g., HIV-1 protease inhibitors). However, to date, none of these has proven effective in randomized controlled trials. On the other hand, the antiviral potential of several small molecules has been demonstrated in cell lines in vitro, but their effectiveness in vivo has not been confirmed $(18,19)$. For the ones that reached animal models, some promising drug candidates have been shown to exacerbate the disease (ribavirin, mycophenolic acid) (20).

Drug development for SARS-CoV-2 and MERS-CoV is of great importance, but considering the diversity of coronaviruses and the proven propensity to cross the species barrier, the SARS-CoV-2 epidemic will probably not be the last one. Warnings about the possibility of another SARS-CoV epidemic have appeared in the scientific literature for a long time (21). Consequently, broad-spectrum antivirals are essential in long-term perspective.

Previously, we demonstrated an antiviral potential of the polymer HTCC [N-(2hydroxypropyl)-3-trimethylammonium chitosan chloride], which efficiently hampered infection of all low-pathogenicity human coronaviruses in vitro and ex vivo (22) and of several animal coronaviruses (unpublished data). Furthermore, using several functional and structural assays, we dissected the mechanism of the HTCC antiviral activity. We showed that the polymer interacts with the coronaviral Spike (S) protein and blocks its interaction with the cellular receptor (22-24). Here, we analyzed HTCC activity against SARS-CoV-2 and MERS-CoV in vitro using permissive cell lines and ex vivo using a model of human airway epithelium (HAE). The study showed that replication of both viruses was efficiently hampered. Overall, our data show that HTCC polymers are potent broad-spectrum anticoronavirals and may be very promising drug candidates for SARS-CoV-2 and MERS-CoV. 


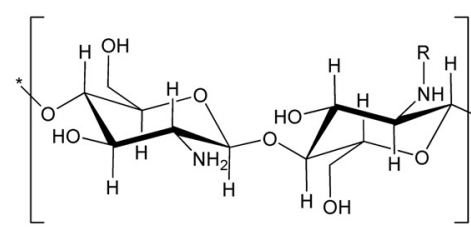

A)

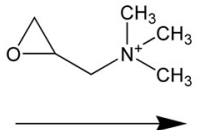

$\mathrm{R}=\mathrm{H}$ or $\mathrm{COCH}_{3}$

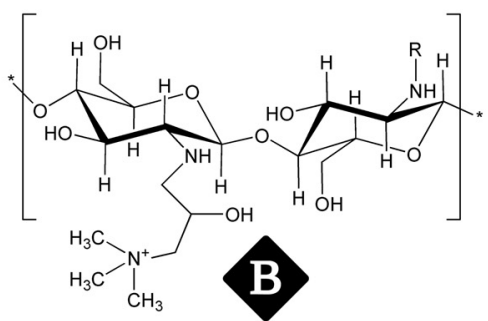

$\mathrm{DS}=10 \%$
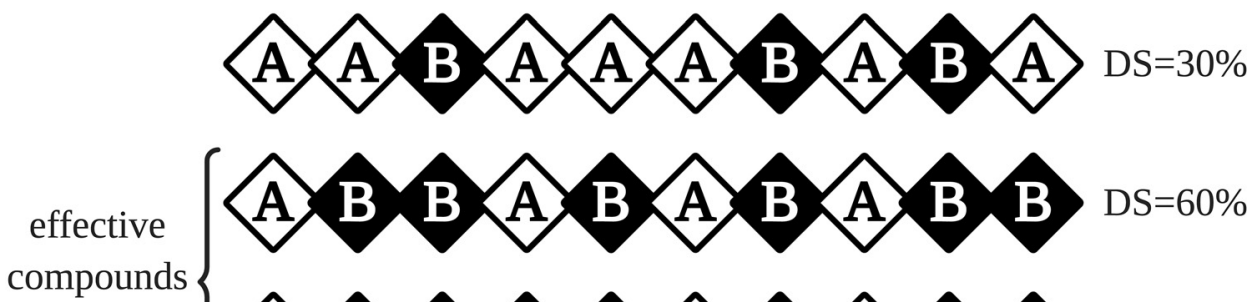
range
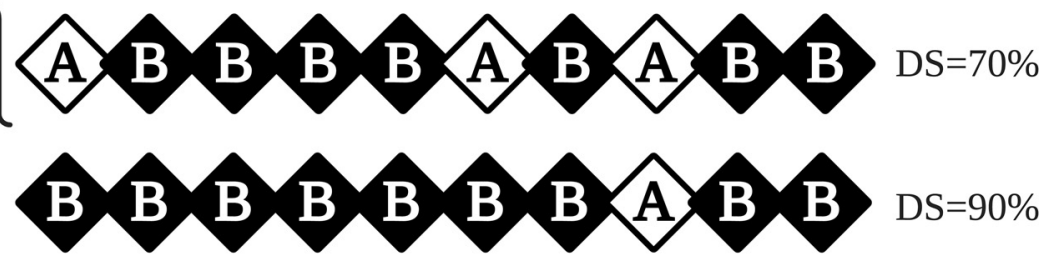

FIG 1 Different HTCC polymers varying in the degree of substitution (DS). The range of effective compounds is $60 \%$ to $70 \%$ degree of substitution of the chitosan chain.

\section{RESULTS AND DISCUSSION}

HTCCs hamper MERS-CoV and SARS-CoV-2 replication in cell lines. Previously, we showed that HTCC with different degrees of substitution (DSs) is a potent inhibitor of all four low-pathogenicity HCoVs (22). DSs are expressed as the fraction of $\mathrm{NH}_{2}$ groups of glucosamine units in chitosan substituted with glycidyltrimethylammonium chloride (GTMAC). The DSs of the studied HTCC polymers ranged between $57 \%$ and 77\%; thus, the polymers were named HTCC-57, HTCC-62, HTCC-63, HTCC-65, and HTCC-77 (Fig. 1). The synthesis and characterization of polymers are described elsewhere $(22,23)$. The analysis showed that HTCC-63 demonstrated the most significant inhibitory effect on HCoV-NL63, HCoV-OC43, and HCoV-HKU1. On the other hand, HTCC62 and HTCC-77 proved to be effective inhibitors of HCoV-229E infection. Further, HTCC65 effectively inhibited the replication of HCoV-NL63 and HCoV-OC43, while HTCC-62 showed a potent antiviral effect on HCoV-HKU1 infection.

First, we determined the cytotoxicity of each HTCC on Vero and Vero E6 cells, which showed that the polymers may be used at a nontoxic concentration of $100 \mu \mathrm{g} / \mathrm{ml}$ (Fig. 2A). Next, the study on MERS-CoV using the Vero cells revealed that all HTCC variants inhibited virus replication to similar extents (approximately 2-fold-to-3-fold decrease in viral yields). The inhibition of the SARS-CoV-2 infection in Vero E6 cells was even more pronounced, and all HTCC variants inhibited virus replication by $\sim 10,000$ times at a nontoxic concentration (Fig. 2B). In this case, the HTCC-63 was arbitrarily selected for further studies on MERS-CoV, while HTCC-77 was selected for SARS-CoV-2. Next, the dose dependence was tested for the HTCCs. The inhibitory activity of selected polymers was verified for three different concentrations, and the obtained data are shown in Fig. 3. Based on the data obtained, the basic parameters were calculated and are presented in Table 1. The parameters observed for the SARS-CoV-2 appear to be 

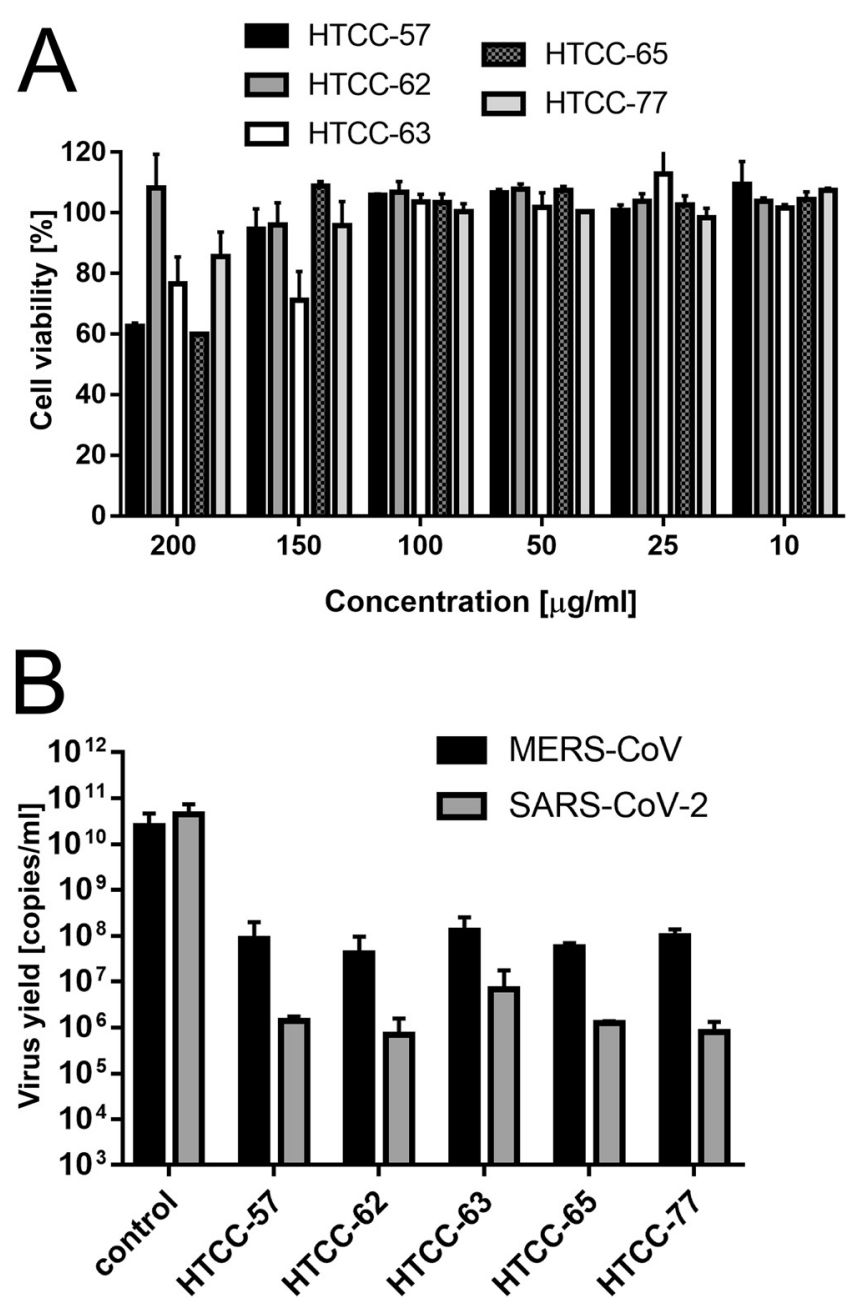

FIG 2 In vitro inhibition of MERS-CoV and SARS-CoV-2 by HTCC at nontoxic concentrations. (A) Cytotoxicity of HTCCs with a degree of substitution ranging from $57 \%$ to $77 \%$ in vitro using Vero and Vero E6 cells. Cell viability was assessed with XTT assay. Data on the $y$ axis represent percentages of values obtained for the untreated reference samples. All assays were performed in triplicate, and average values obtained for both cell lines with standard errors are presented. (B) Vero cells were infected with MERS-CoV, and Vero E6 cells were infected with SARS-CoV-2. Briefly, cultures were inoculated with a given virus in the presence of HTCC $(100 \mu \mathrm{g} / \mathrm{ml})$ or control PBS. Replication of viruses was evaluated at $48 \mathrm{~h}$ postinoculation using RT-qPCR. The data are presented as the number of viral RNA copies per milliliter. The assay was performed in triplicate, and average values with standard errors are shown.

favorable, with a selectivity index (SI) value above 12. It is also worth noting that HTCC was previously administered by inhalation in rats and that no adverse reactions were observed (25). In that study, HTCC was used as a carrier for the active substance and, as such, was reported to be promising for local sustained inhalation therapy of pulmonary diseases.

Furthermore, to prove the HTCC activity in vitro, Vero (MERS-CoV) and Vero E6 (SARS-CoV-2) cells were infected with a given virus in the presence of the compounds. After $24 \mathrm{~h}$ of culture at $37^{\circ} \mathrm{C}$, cells were collected, lysed, and subjected to SDS-PAGE. Western blot detection of nucleocapsid proteins showed a dose-dependent reduction of each virus infection, as $\mathrm{N}$ protein levels declined in the presence of the HTCCS (Fig. 4).

HTCC interacts with the coronaviral spike protein. First, we made an effort to delineate at which stage the HTCC interferes with the virus replication. We have previously shown that HTCC blocks the interaction between the coronaviral S protein and 

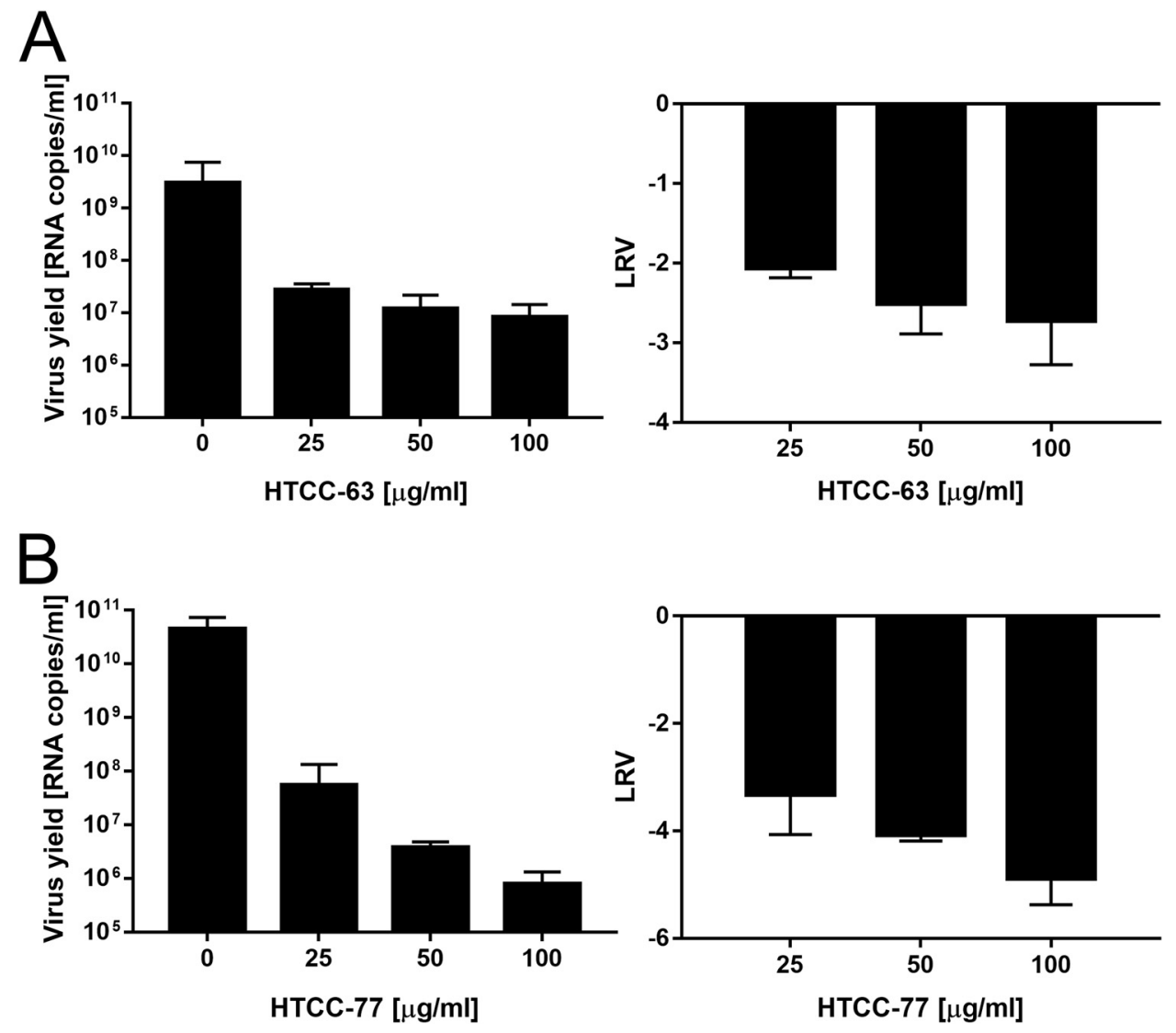

FIG 3 Dose-dependent inhibition of MERS-CoV and SARS-CoV-2 replication. Vero cells (MERS-CoV) (A) or Vero E6 cells (SARS-CoV-2) (B) were inoculated with a given virus in the presence of different concentrations of HTCC. Replication of viruses was evaluated at $48 \mathrm{~h}$ postinoculation using RT-qPCR. The data are presented as the number of viral RNA copies per milliliter (left panel) and as log removal value (LRV) compared to the untreated sample (right panel). The assay was performed in triplicate, and average values with standard errors are displayed. All the results are statistically significant, as determined using the Student's $t$ test.

its cellular receptor (23). Here, using a set of functional assays, we showed that pretreatment of cells did not result in inhibition of viral replication, while the presence of HTCC during the infection blocked the process (Fig. 5). The observed inhibition of replication when the HTCC was present throughout the infection resulted most likely from the multicycle infection process. However, an additional inhibitory effect on the replication itself must be considered.

Second, we aimed to verify whether the polymer interacts with the coronaviral S protein, as previously shown for HCoV-NL63 (23). For this, we analyzed the fluorescence spectra of HTCC-fluorescein isothiocyanate isomer 1 (HTCC-FITC) in the presence of the SARS-CoV-2 or MERS-CoV spike proteins (S1 domains). Gelatin was used as a reference. The analysis showed that both proteins quenched the fluorescence emission and that the relative fluorescence of HTCC-FITC decreased with the increase in SARSCoV-2 and MERS-CoV S1 concentrations, but not gelatin concentrations, in a nonlinear manner (Fig. 6A and B). The plot shape for that dependence indicated that HTCC-FITC

TABLE $1 \mathrm{CC}_{50}, \mathrm{IC}_{50}$, and SI values for the two most effective HTCCs: HTCC-63 (for MERS-CoV) and HTCC-77 (for SARS-CoV-2) ${ }^{a}$

\begin{tabular}{llll}
\hline Virus & $\mathrm{CC}_{50}(\mu \mathrm{g} / \mathrm{ml})$ & $\mathrm{IC} 50(\mu \mathrm{g} / \mathrm{ml})$ & $\mathrm{SI}\left(\mathrm{CC}_{50} / \mathrm{IC}_{50}\right)$ \\
\hline MERS-CoV & 161.0 & 62.8 & 2.6 \\
SARS-CoV-2 & 158.0 & 12.5 & 12.6 \\
\hline
\end{tabular}

${ }^{a} \mathrm{CC}_{50}, 50 \%$ cytotoxic concentration; $\mathrm{IC}_{50}, 50 \%$ inhibitory concentration; SI, selectivity index. 


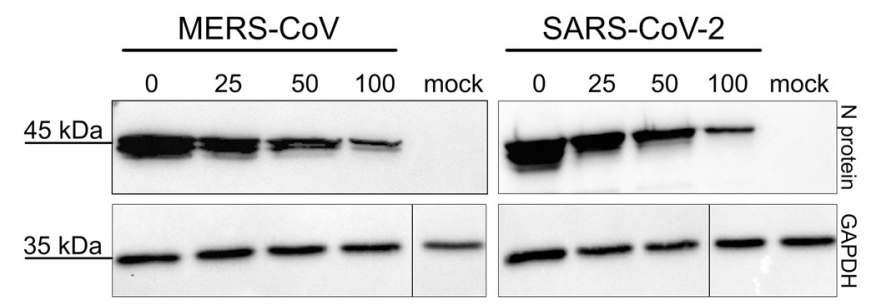

FIG 4 Dose-dependent inhibition of MERS-CoV and SARS-CoV-2 infection. Vero cells (MERS-CoV) (left panels) or Vero E6 cells (SARS-CoV-2) (right panels) were inoculated with a given virus in the presence of different concentrations of HTCC (HTCC-63 for MERS-CoV; HTCC-77 for SARS-CoV-2). Following incubation for $24 \mathrm{~h}$ at $37^{\circ} \mathrm{C}$, cells were lysed in RIPA buffer. Nucleocapsid proteins and control GAPDH protein were detected by Western blotting using specific antibodies.

was not quenched by these proteins in a simple diffusion-controlled collisional process but that there were specific interactions between these macromolecules (Fig. 6B). Such dependence is observed typically when the interaction between the chromophore and the quencher leads to a complex formation $(26,27)$. To further verify that observation, experimental data were fitted to a modified Stern-Volmer equation (27):

$$
I_{0} /\left(I_{0}-I\right)=1 /([Q]) \cdot 1 / f_{a} 1 / K_{a}+1 / f_{a}
$$

\begin{tabular}{cccc}
\hline Target & Polymer & Assay & PFU/ml \\
\hline & & Pre & $8533.3 \pm 585.0$ \\
MERS-CoV & During & Below detection limit \\
& Post & Below detection limit \\
& Control & $8800.0 \pm 824.6$ \\
\hline & Pre & $38500.0 \pm 11500.0$ \\
SARS-CoV-2 & HTCC-77 & During & $4333.3 \pm 111.1$ \\
& & Post & $4800.0 \pm 2133.3$ \\
& Control & $48666.7 \pm 3666.7$ \\
\hline
\end{tabular}

B

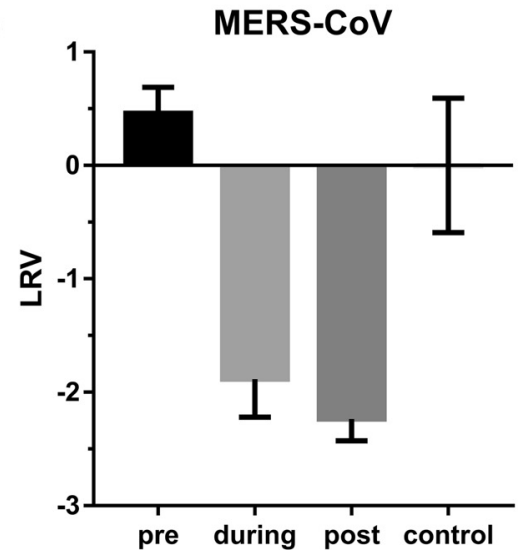

SARS-CoV-2

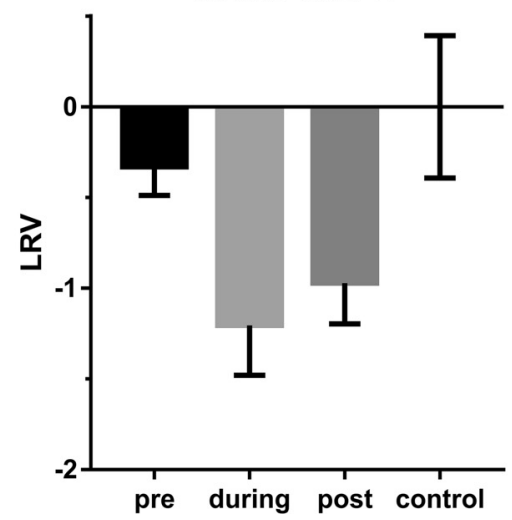

FIG 5 HTCC hampers interaction between the virus and the cell. Vero cells (MERS-CoV) or Vero E6 cells (SARSCoV-2) were inoculated with a virus in the presence of HTCC (HTCC-63 for MERS-CoV; HTCC-77 for SARS-CoV2). Polymers were applied in three different manners: for assay I, pre-cells were pretreated with compounds before infection; for assay II, during-polymers were added alongside the virus and were present throughout the incubation; for assay III, post-polymers were added $1 \mathrm{~h}$ after the infection. Replication of viruses was evaluated at $48 \mathrm{~h}$ postinfection using plaque assay (A) and RT-qPCR (B). 
A

SARS-CoV-2

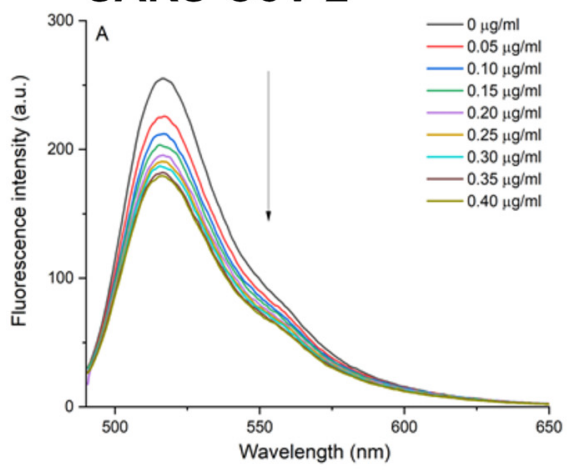

B
MERS-CoV

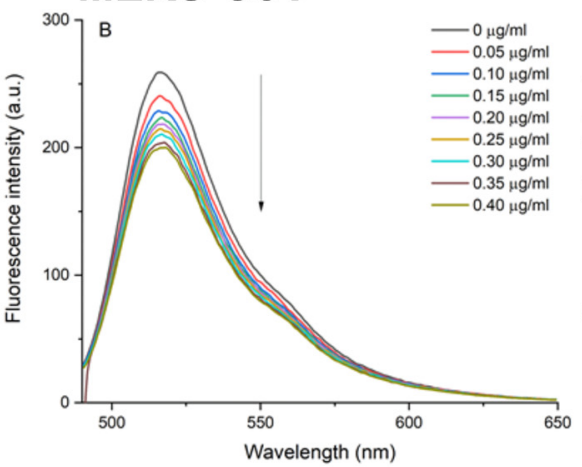

Gelatin

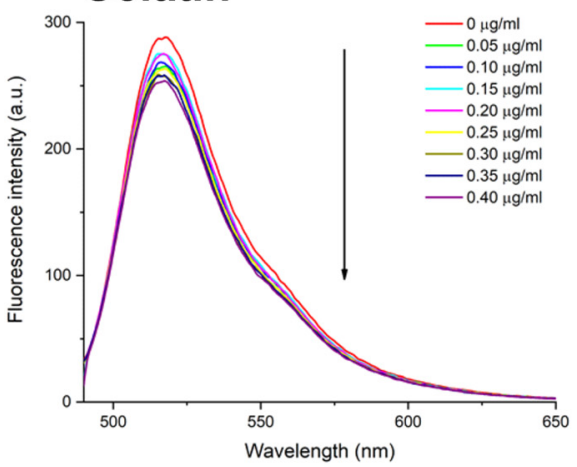

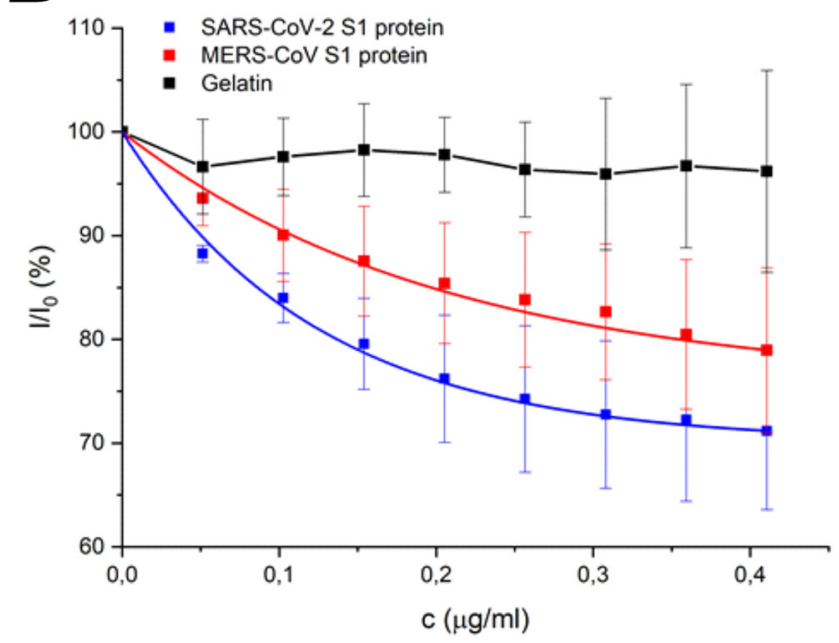

C

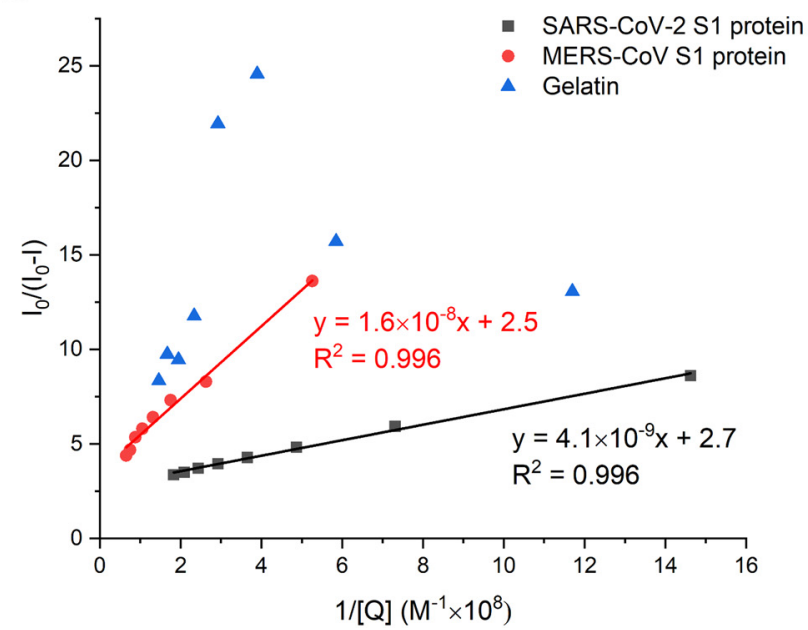

FIG 6 Interaction between HTCC-FITC and SARS-CoV-2 S1 domain. (A) Fluorescence spectra of HTCC-FITC (excitation wavelength $\left[\lambda_{\text {ex }}\right]=470$ nm; cHTCC$\mathrm{FITC}=0.5 \mu \mathrm{g} / \mathrm{ml}$ ) in the absence and in the presence of SARS-CoV-2, MERS-CoV S1, or gelatin proteins at various concentrations. a.u., arbitrary units. (B) Dependence of relative fluorescence intensity (I/I0) of HTCC-FITC (emission wavelength $\left[\lambda_{\text {em }}\right]=517 \mathrm{~nm}$ ) on the concentration of SARS-CoV-2, MERS-CoV S1, and gelatin. (C) Dependence of relative fluorescence I0/(I0-I) of HTCC-FITC on 1/[Q] for SARS-CoV-2 S1 protein and MERS-CoV S1 protein.

where $I_{0}$ is the fluorescence intensity of HTCC-FITC in the absence of S1, $I$ is the fluorescence intensity of FITC-HTCC in the presence of S1, [Q] is the concentration of $\mathrm{S} 1, f_{a}$ is the fraction of FITC chromophores in HTCC-FITC available for quenching by S1, and $K_{a}$ is a modified Stern-Volmer quenching constant for the accessible FITC residues. The results are presented in Fig. $6 \mathrm{C}$. The analysis indicated that the fraction of polymeric chromophores available for interaction with SARS-CoV-2 and MERS S1 proteins in both cases was $\sim f_{a}=0.4$. This rather low value is understandable, as a specific orientation of both macromolecules is necessary to allow their effective interaction within a complex. Strong interaction between HTCC-FITC and S1 can be inferred based on the efficient quenching process indicated by the high value of $K_{a}$, which was found to be equal to $6.59 \times 10^{8} \mathrm{M}^{-1}$ for SARS-CoV-2 S1 and $1.56 \times 10^{8} \mathrm{M}^{-1}$ for MERS-CoV S1. The stronger interactions between HTCC and SARS-CoV-2 S1 correspond with more-efficient replication inhibition of that virus in cell culture and confirm the proposed mechanism.

HTCCs hamper MERS-COV and SARS-CoV-2 replication in human airway epithelium. While the Vero cells constitute a convenient model for antiviral research, it is of utmost importance to verify whether the results obtained are not biased due to the artificial system used. This is especially important for compounds, for which activity is based on electrostatic interaction. To verify whether the natural microenvironment, which is rich in sugars and charged molecules, does not abrogate the effectiveness of 

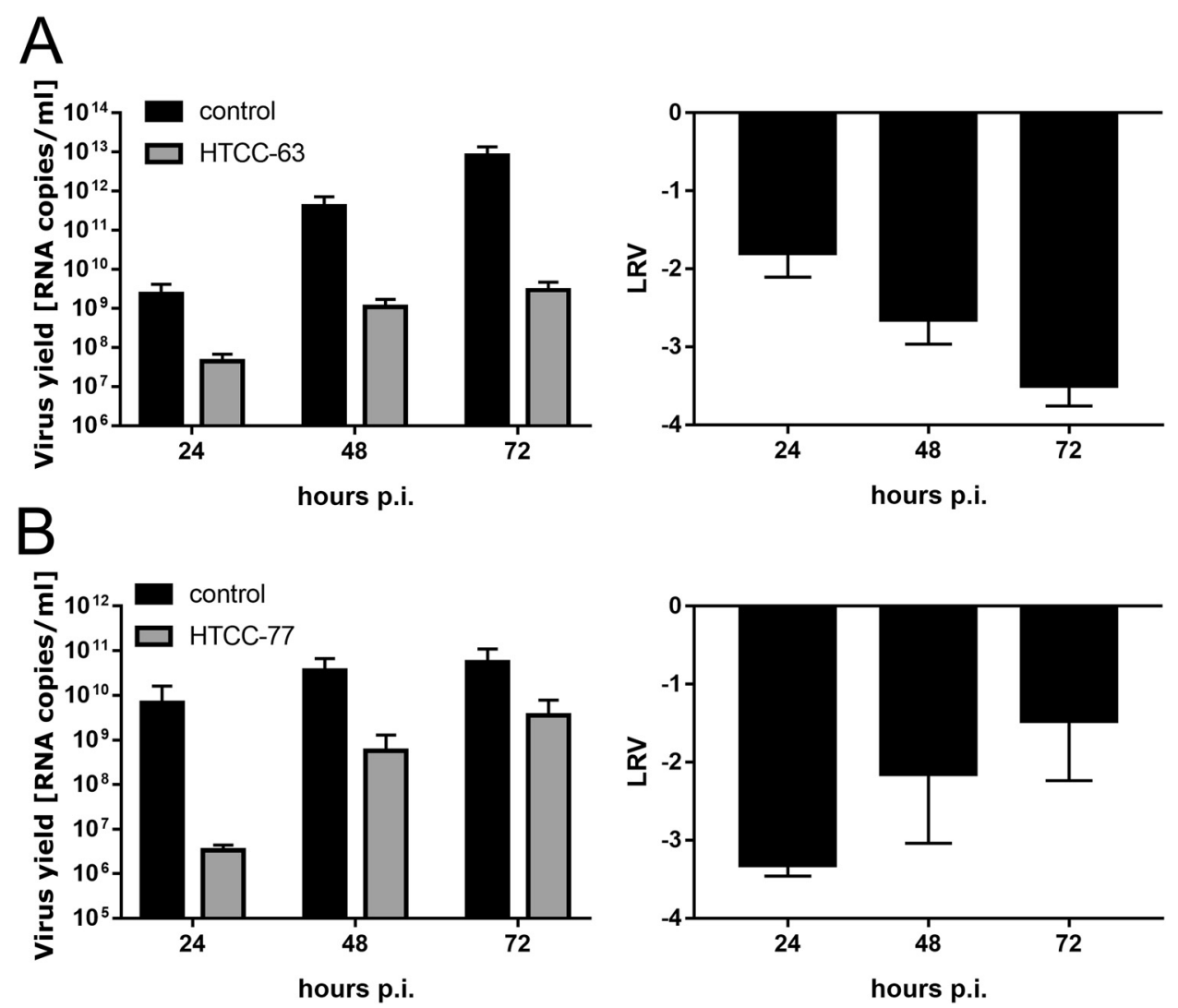

FIG 7 Ex vivo inhibition of MERS-CoV and SARS-CoV-2 by HTCC in human airway epithelium cultures. HAE cultures were exposed to MERS-CoV (A) or SARS-CoV-2 (B) in the presence of HTCC-63 (for MERS-CoV) or HTCC-77 (for SARS-CoV-2) at $200 \mu \mathrm{g} / \mathrm{ml}$ or to control PBS. To analyze virus replication kinetics, each day postinfection, $100 \mu \mathrm{l}$ of $1 \times$ PBS was applied to the apical surface of HAE cultures and collected after $10 \mathrm{~min}$ of incubation at $37^{\circ} \mathrm{C}$. Replication of viruses was evaluated using RT-qPCR. The data are presented as the number of viral RNA copies per $\mathrm{ml}$ (left panel) and as log removal value (LRV) compared to the untreated sample (right panel). The assay was performed in triplicate, and average values with standard errors are shown. All the results are statistically significant, as determined using the Student's $t$ test.

the inhibitors, we employed HAE cultures that mirror the fully differentiated layer lining the conductive airways, as well as the site of coronavirus replication. Briefly, fully differentiated HAE cultures were infected with a given virus (28) in the presence of previously selected HTCCs $(200 \mu \mathrm{g} / \mathrm{ml})$ or control phosphate-buffered saline (PBS). Following inoculation, apical lavage samples were collected daily, and the replication kinetics for each virus was investigated. The analysis revealed that the polymer efficiently hampered SARS-CoV-2 and MERS-CoV also in this model. For MERS-CoV, the inhibitory effect was the most evident at $72 \mathrm{~h}$ postinfection (p.i.), while for SARS-CoV-2, the most substantial decline of virus progeny was observed at $24 \mathrm{~h}$ p.i. (Fig. 7). Whether such kinetics would be reflected in vivo is to be investigated.

HTCCs inhibits MERS-CoV and SARS-CoV-2 entry into susceptible cells. Our previous research showed that the HTCC-mediated inhibition of coronaviral replication results from the electrostatic interaction between the polymer and the Spike protein of coronaviruses. We hypothesize that the selectivity of the inhibitors is a consequence of the yields from the fitting charge distributions on the polymer and on the $S$ proteins on the viral surface. While the interaction with a single charged moiety is relatively weak, the concatemeric nature of the virus and the polymer stabilizes the binding. Such structure-based interactions may be an interesting entry point for further finetuning of the polymeric inhibitors of viral replication.

To ensure that the observed effect was a result of coronavirus entry inhibition by 
HTCC, two experiments were performed. First, HAE cultures were inoculated with MERS-CoV in the presence of HTCC-63 $(200 \mu \mathrm{g} / \mathrm{ml})$ or control PBS and incubated for 2 $\mathrm{h}$ at $37^{\circ} \mathrm{C}$. Next, cells were fixed and immunostained for MERS-CoV N protein and actin. Virus entry was analyzed with confocal microscopy. To visualize the effect, the signal attributed to intracellular MERS-CoV was quantified, and the results show that the internalization of MERS-CoV was drastically decreased (Fig. 8A and B). Due to the limited availability of tools for the SARS-CoV-2 at that time, we were not able to replicate the experiment. Here, we employed a surrogate system based on lentiviral vectors pseudotyped with full-length Spike protein of SARS-CoV-2. A549 cells overexpressing the ACE2 protein were incubated with pseudovirions harboring SARS-CoV-2 Spike or control vesicular stomatitis virus G (VSV-G) protein in the presence of HTCC-77 $(100 \mu \mathrm{g} / \mathrm{ml})$ or control PBS for $2 \mathrm{~h}$ at $37^{\circ} \mathrm{C}$. After $72 \mathrm{~h}$ p.i., cells were lysed, and pseudovirus entry was quantified by measurement of the reporter luciferase protein. The analysis showed a significant reduction in internalization of the SARS-CoV-2 Spike pseudoviruses in the presence of the polymer, while no inhibition was observed for the control VSV-G (Fig. 8C).

Next, to verify whether the mechanism of action for the highly pathogenic betacoronaviruses is similar to that observed for alphacoronaviruses (22) and that it is based on blocking the interaction between the virus and the entry receptor, we analyzed MERS-CoV colocalization with its entry receptor, DPP4, in the presence or absence of the HTCC. For this, human cell line Huh7 was inoculated with the virus or subjected to mock treatment in the presence of HTCC-63 $(100 \mu \mathrm{g} / \mathrm{ml})$ or control PBS and incubated for $2 \mathrm{~h}$ at $4^{\circ} \mathrm{C}$. Subsequently, cells were fixed and immunostained for the DPP4 and MERS-CoV N using specific antibodies. Virus colocalization with its receptor was examined using confocal microscopy. Obtained results demonstrated that in the control samples, the signal originating from the N protein colocalized with the DPP4 protein, while in the presence of the polymer, this interaction was blocked (Fig. 9).

We show here that the previously developed and described polymeric anticoronaviral HTCC compounds can efficiently inhibit infection with emerging coronaviruses. We believe that the HTCC can be fine-tuned to target any coronavirus and that this interaction is specific to viruses that belong to the Coronaviridae family. One may speculate that the inhibition results from the concatemeric nature of the virus surface and the fact that the polymer with appropriate charge distribution can interact with multiple sites on this surface. While the interaction of the monomer is relatively weak and no inhibition is observable for monomers, the sum of interactions stabilizes the binding and specific inhibition is observed. Considering that the extended chain length for the HTCC used is $\sim 700 \mathrm{~nm}$, this scenario seems realistic (29). If it is true, HTCC would constitute the first known structure-specific inhibitor of viral replication. The major disadvantage associated with HTCC is that, at present, it is not registered for use in humans. However, previous experience with HTCC in different laboratories showed that it may be delivered topically to the lungs, it is not associated with toxicity, and it does not worsen the lung function (25). We believe that HTCC is a promising drug candidate that should be further studied, as it provides a ready-to-use solution for the problems posed by SARS-CoV-2 and future emerging coronaviruses.

\section{MATERIALS AND METHODS}

Materials. Chitosan (low molecular weight [MW], viscometric molecular weight [Mv] = 50 to $190 \mathrm{kDa}$, degree of deacetylation DDA $=73 \%$ based on elemental analysis; Sigma-Aldrich), glycidyltrimethylammonium chloride (GTMAC; Sigma-Aldrich), fluorescein isothiocyanate isomer 1 (FITC; Sigma-Aldrich), glacial acetic acid (ChemPur) $\left(\mathrm{CH}_{3} \mathrm{COOH} ; 99.5 \%\right.$ pure p.a.), acetone (Sigma-Aldrich), ethanol (Stanlab), AgNO3 (Sigma-Aldrich), dimethyl sulfoxide (DMSO; POCh), and pyridine (Sigma-Aldrich) were used as received. Recombinant SARS-CoV-2 Spike protein (S1 subunit derived from Escherichia coli; $\mathrm{MW}=75 \mathrm{kDa}$ ) and MERS (S1 fragment [amino acids \{aa\} 56 to 296] derived from E. coli; MW= $27 \mathrm{kDa}$ ) were purchased from RayBiotech. Gelatin from bovine skin (type B) was purchased from Sigma-Aldrich. Water was distilled twice and deionized using a Millipore Simplicity system.

The active compound. The HTCC was prepared in the same manner as previously described $(22,23$, 30). Briefly, $30 \mathrm{ml}$ of GTMAC was added to the chitosan solution in dilute acetic acid ( $3 \mathrm{~g}$ of chitosan and $150 \mathrm{ml}$ of $1 \%$ [vol/vol] acetic acid solution in water). The solution was stirred at $70^{\circ} \mathrm{C}$ for $24 \mathrm{~h}$ and then 

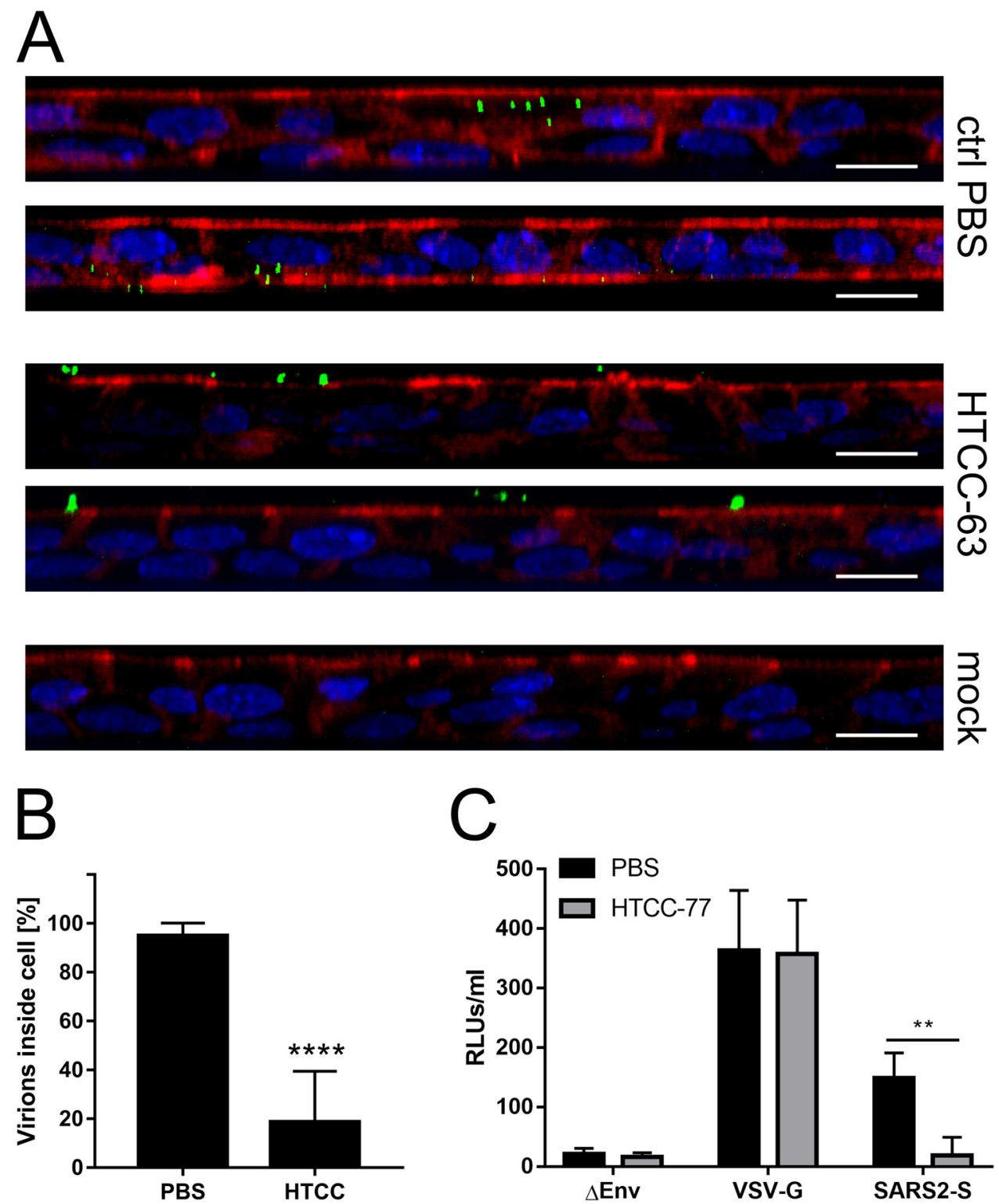

FIG 8 Coronavirus internalization into susceptible cells is hampered by HTCC. (A and B) Precooled HAE cultures were incubated with an ice-cold MERS-CoV suspension in the presence or absence of HTCC- $63(200 \mu \mathrm{g} / \mathrm{ml})$ for $2 \mathrm{~h}$ at $37^{\circ} \mathrm{C}$. Next, cells were fixed in paraformaldehyde (PFA) and immunostained for MERS-CoV N protein and actin. Virus entry was analyzed with confocal microscopy. The data shown are representative of results from three independent experiments, each performed in triplicate. Mann-Whitney test, ${ }^{* * * *}, P<0.0001$. (C) A549 cells overexpressing ACE2 were incubated with lentiviral particles bearing the firefly luciferase reporter gene and pseudotyped with SARS-CoV-2 Spike (SARS-S2-S) or VSV control G protein (VSV-G) or particles without an envelope protein ( $\triangle$ Env) in the presence of HTCC-77 or control PBS. After $2 \mathrm{~h}$ at $37^{\circ} \mathrm{C}$, cells were washed with PBS and overlaid with fresh medium. Following $72 \mathrm{~h}$ of incubation, cells were lysed, and luminescence signal was measured using a spectrophotometer. Pseudovirus entry data are presented as relative luminescence units per milliliter (RLUs/ml). The assay was performed in triplicate, and average values with standard errors are presented. Student's $t$ test, ${ }^{* *}, P<0.005$.

centrifuged at 4,000 rpm for $10 \mathrm{~min}$ to remove unreacted chitosan. The product was precipitated from the supernatant with a cold mixture of acetone and ethanol (4:1 [ $\mathrm{vol} / \mathrm{vol}])$. The solution was decanted, and the resulting precipitate was dissolved in distilled water. The purification process was repeated, the resulting pellet was washed with ethanol three times, and the purified HTCC was dried in a vacuum oven for $24 \mathrm{~h}$. The degree of substitution (DS) of $\mathrm{NH}_{2}$ groups of the aminoglucose units in GTMAC was found to be $69 \% \pm 2 \%$ as determined via conductometric titration of the chloride anion with a $0.017 \mathrm{M}$ solution of $\mathrm{AgNO}_{3}$.

Synthesis of fluorescein-labeled HTCC (HTCC-FITC). A 250-mg volume of HTCC was suspended in a mixture of DMSO and pyridine (21 ml, 20:1 [vol/vol] $)$. A 15-mg volume of fluorescein isothiocyanate 

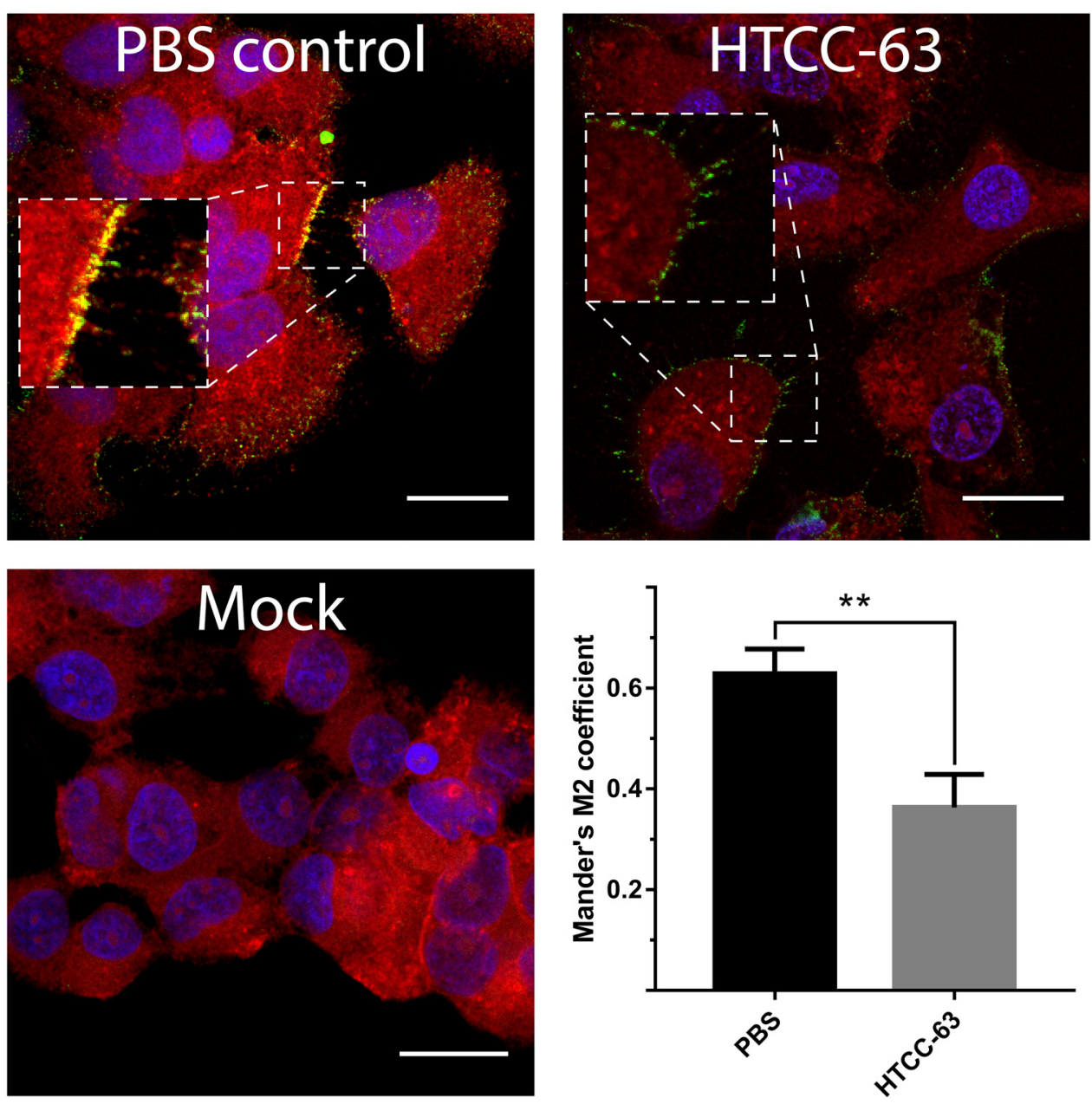

FIG 9 HTCC blocks the interaction between the virus and its entry receptor. Precooled Huh7 cells were incubated for $3 \mathrm{~h}$ at $4^{\circ} \mathrm{C}$ with ice-cold MERS-CoV or subjected to mock treatment in the presence or absence of HTCC-63 $(100 \mu \mathrm{g} / \mathrm{ml})$. Next, cells were fixed with PFA and immunostained for MERS-CoV-N (green), DPP4 (red), and nuclear DNA (blue). MERS-CoV interaction with the DPP4 protein was analyzed with confocal microscopy. Colocalization of DPP4 with MERS-CoV-N was determined by confocal microscopy, and the results are presented as Manders' M2 coefficient values after excluding nonspecific nuclear signal. Colocalization analysis was carried out with ImageJ JACoP (Just Another Colocalization Plugin). The decrease in colocalization was statistically significant $(P<0.0005)$. Each image represents a single axial plane. Representative images are shown. Bar, $20 \mu \mathrm{m}$.

(FITC) was dissolved in $5 \mathrm{ml}$ of DMSO and added to a vigorously stirred suspension of HTCC. The reaction mixture was stirred for $24 \mathrm{~h}$ in $95^{\circ} \mathrm{C}$ in the dark. The crude product was dialyzed against water and freeze-dried. In its absorption spectra, a band was present with a maximum wavelength $\left(\lambda_{\max }\right)$ of $494 \mathrm{~nm}$ in water, confirming the substitution of HTCC with FITC. The degree of substitution of HTCC with FITC, defined as the number of FITC groups per aminoglucose group of HTCC and calculated based on the UV-Vis (UV-visible light) spectra, was equal to $2.3 \%$.

Plasmid constructs. The codon-optimized full-length SARS-CoV-2 S gene was designed and purchased from GeneArt (Thermo Fisher Scientific, Poland). The gene was cloned into PCAGGS and sequence verified that was a gift from Xingchuan Huang. psPAX (Addgene plasmid no. 12260) and pMD2G (Addgene plasmid no. 12259) were gifts from Didier Trono. pRRL luciferase vector (Addgene plasmid no. 120798) was a gift from Paul Khavari.

Cell culture. Vero and Vero E6 cells (Cercopithecus aethiops; kidney epithelial; ATCC CCL-81 and ATCC CRL-1586), Huh7 cells (Homo sapiens; hepatocellular carcinoma; ECACC 01042712) and A549 cells with ACE2 overexpression (A549 ${ }^{A C E 2+}$ ) (31) were cultured in Dulbecco's modified Eagle medium (MEM) (Thermo Fisher Scientific, Poland) supplemented with 3\% fetal bovine serum (heat inactivated; Thermo Fisher Scientific, Poland) and the following antibiotics: penicillin (100 U/ml), streptomycin $(100 \mu \mathrm{g} / \mathrm{ml})$, and ciprofloxacin $(5 \mu \mathrm{g} / \mathrm{ml})$. Cells were maintained at $37^{\circ} \mathrm{C}$ under $5 \% \mathrm{CO}_{2}$.

Human airway epithelium (HAE) cultures. Human airway epithelial cells were isolated from conductive airways resected from transplant patients. The study was approved by the Bioethical Committee of the Medical University of Silesia in Katowice, Poland (approval no KNW/0022/KB1/17/10, dated 16 
February 2010). Written consent was obtained from all patients. Cells were dislodged by protease treatment and were later mechanically detached from the connective tissue. Further, cells were trypsinized and transferred onto permeable Transwell insert supports $(\phi=6.5 \mathrm{~mm})$. Cell differentiation was stimulated by the medium additives, and removal of media from the apical side was performed after the cells reached confluence. Cells were cultured for 4 to 6 weeks to form well-differentiated, pseudostratified mucociliary epithelia. All experiments were performed in accordance with relevant guidelines and regulations.

Cell viability assay. HAE cultures were prepared as described above. The cell viability assay was performed by using the 2,3-bis-(2-methoxy-4-nitro-5-sulfophenyl)-2H-tetrazolium-5-carboxanilide salt (XTT) cell viability assay (Biological Industries, Israel) according to the manufacturer's instructions. On the day of the assay, $100 \mu \mathrm{l}$ of $1 \times$ PBS was added with $50 \mu \mathrm{l}$ of the activated XTT solution to each well/culture insert. Following $2 \mathrm{~h}$ of incubation at $37^{\circ} \mathrm{C}$, the solution was transferred onto a 96-well plate, and the signal was measured at $\lambda=490 \mathrm{~nm}$ using a SpectraMax 250 colorimeter (Molecular Devices). The obtained results were further normalized to the control sample, where cell viability was set to $100 \%$.

Virus preparation and titration. MERS-CoV stock (isolate England 1, no. 1409231v; National Collection of Pathogenic Viruses, Public Health England, United Kingdom) was generated by infecting monolayers of Vero cells. SARS-CoV-2 stock (isolate 026V-03883; kindly provided by Christian Drosten, Charité-Universitätsmedizin Berlin, Berlin, Germany, and the European Virus Archive-Global [EVAg]; https://www.european-virus-archive.com/) was generated by infecting monolayers of Vero E6 cells. The virus-containing liquid was collected at day 3 postinfection (p.i.), aliquoted, and stored at $-80^{\circ} \mathrm{C}$. Control Vero or Vero E6 cell lysate from mock-infected cells was prepared in the same manner. Virus yield was assessed by titration on fully confluent Vero or Vero E6 cells in 96-well plates, according to the method of Reed and Muench. Plates were incubated at $37^{\circ} \mathrm{C}$ for 3 days, and the cytopathic effect (CPE) was scored by observation under an inverted microscope.

Virus infection. In in vitro experiments, fully confluent Vero, Vero E6, or Huh7 cells in 96-well plates (TPP) were exposed to MERS-CoV or SARS-CoV-2 or were subjected to mock treatment at a $50 \%$ tissue culture infective dose $\left(\mathrm{TCID}_{50}\right)$ of 400 per $\mathrm{ml}$ in the presence of tested polymer or control medium. Following $2 \mathrm{~h}$ of incubation at $37^{\circ} \mathrm{C}$, unbound virions were removed by washing with $100 \mu \mathrm{l}$ of $1 \times \mathrm{PBS}$ and fresh medium containing dissolved respective polymer was added to each well. Samples of cell culture supernatant were collected at day 3 p.i. and analyzed using reverse transcription-quantitative PCR (RT-qPCR).

For the ex vivo study, fully differentiated human airway epithelium (HAE) cultures were exposed to the tested polymer or control PBS for $30 \mathrm{~min}$ at $37^{\circ} \mathrm{C}$, following inoculation with MERS-CoV or SARS-CoV2 at a $\mathrm{TCID}_{50}$ of 400 per $\mathrm{ml}$ in the presence of the polymer or control PBS. Following $2 \mathrm{~h}$ of incubation at $37^{\circ} \mathrm{C}$, unbound virions were removed by washing with $200 \mu \mathrm{l}$ of $1 \times \mathrm{PBS}$, and HAE cultures were maintained at the air-liquid interphase for the rest of the experiment. To analyze virus replication kinetics, each day p.i., $100 \mu \mathrm{l}$ of $1 \times$ PBS was applied at the apical surface of HAE and collected following a 10-min incubation at $32^{\circ} \mathrm{C}$. All samples were stored at $-80^{\circ} \mathrm{C}$ and analyzed using RT-qPCR.

Functional assays. To delineate the mechanism of action for the HTCC, a set of functional assays was carried out. Fully confluent Vero or Vero E6 cells in 48-well plates were exposed to MERS-CoV or SARS-CoV-2, respectively, at 400 TCID $_{50}$ per ml. HTCC-63 was used for MERS-CoV and HTCC-77 for SARSCoV-2. First, the ability of polymers to interact with a cell to prevent infection was examined (assay I-pre). Briefly, cells were overlaid with the test compound or control PBS and incubated for $1 \mathrm{~h}$ at $37^{\circ} \mathrm{C}$. Subsequently, the polymer was removed by a triple wash with $1 \times \mathrm{PBS}$, and a virus or a mock treatment was added. After $2 \mathrm{~h}$ of infection at $37^{\circ} \mathrm{C}$, cells were washed and further cultured in fresh medium for 48 $\mathrm{h}$ at $37^{\circ} \mathrm{C}$. Next, the influence of polymers on virus-cell interactions was inspected (assay II-during). Cells were infected in the presence of compounds or control PBS and incubated at $37^{\circ} \mathrm{C}$. After $2 \mathrm{~h}$, cells were washed twice with $1 \times$ PBS, fresh culture medium with polymers was applied, and cells were cultured for $48 \mathrm{~h}$ at $37^{\circ} \mathrm{C}$. In the third assay (assay III-post), the effects of compounds on virus replication, assembly, and egress were evaluated. Cells were infected and incubated for $2 \mathrm{~h}$ at $37^{\circ} \mathrm{C}$. Subsequently, unbound virions were removed with two washes with $1 \times \mathrm{PBS}$, and media supplemented with polymers or control PBS were applied. Cells were then cultured for $48 \mathrm{~h}$ at $37^{\circ} \mathrm{C}$. Samples of supernatant were collected at day 2 p.i. and analyzed using qPCR and plaque assay.

Plaque assay. Vero E6 cells were seeded in 24-well plates and grown to $90 \%$ confluence. Tenfold serial dilutions of previously collected samples in culture medium were prepared and placed on cells. Following $1 \mathrm{~h}$ of incubation in $37^{\circ} \mathrm{C}$, an equal volume of $2 \times$ overlay media (DMEM supplemented with $4 \%$ fetal bovine serum, penicillin [100 U/ml], streptomycin [100 $\mu \mathrm{g} / \mathrm{ml}]$, and $0.1 \%$ agarose) was added to the inoculum and the cultures were incubated for 3 days at $37^{\circ} \mathrm{C}$ under stationary conditions. Next, cells were fixed with $4 \%$ paraformaldehyde, stained using $0.1 \%$ crystal violet solution, and washed with tap water, and plaques were counted.

Isolation of nucleic acids and reverse transcription (RT). A viral DNA/RNA kit (A\&A Biotechnology, Poland) was used for nucleic acid isolation from cell culture supernatants, according to the manufacturer's instructions. CDNA samples were prepared with a High-Capacity CDNA reverse transcription kit (Thermo Fisher Scientific, Poland), according to the manufacturer's instructions.

Quantitative PCR (qPCR). Viral RNA yield was assessed using real-time PCR (7500 Fast real-time PCR; Life Technologies, Poland). CDNA was amplified in a reaction mixture containing $1 \times$ qPCR master mix (A\&A Biotechnology, Poland), in the presence of a probe ( $100 \mathrm{nM})$ and primers ( $450 \mathrm{nM}$ each) (Table 2). The reaction was carried out according to the following scheme: 2 min at $50^{\circ} \mathrm{C}$ and $10 \mathrm{~min}$ at $92^{\circ} \mathrm{C}$, followed by 40 cycles of $15 \mathrm{~s}$ at $92^{\circ} \mathrm{C}$ and $1 \mathrm{~min}$ at $60^{\circ} \mathrm{C}$. In order to assess the copy number for the $\mathrm{N}$ gene, DNA standards were prepared as described before (28). 
TABLE 2 Primers and probes ${ }^{a}$

\begin{tabular}{lll}
\hline Primer or probe & MERS-CoV & SARS-CoV-2 \\
\hline $5^{\prime}$ primer & GGG TGT ACC TCT TAA TGC CAA TTC & CAC ATT GGC ACC CGC AATC \\
3' primer & TCT GTC CTG TCT CCG CCA AT & GAG GAA CGA GAA GAG GCT TG \\
Probe & ACC CCT GCG CAA AAT GCT GGG (FAM/TAMRA) & ACT TCC TCA AGG AAC AAC ATT GCC A (FAM/BHQ1) \\
\hline
\end{tabular}

${ }^{a}$ FAM, 6-carboxyfluorescein; TAMRA, 6-carboxytetramethylrhodamine; BHQ1, black hole quencher 1.

Immunostaining and confocal imaging. Fixed cells were permeabilized with $0.1 \%$ Triton X-100$1 \times$ PBS and incubated overnight at $4^{\circ} \mathrm{C}$ in $1 \times$ PBS supplemented with $5 \%$ bovine serum albumin (BSA) and $0.5 \%$ Tween 20. To visualize MERS-CoV particles, cells were incubated for $2 \mathrm{~h}$ at room temperature with mouse anti-MERS-CoV N IgGs (Sino Biological, China) (1:1,000 dilution), followed by $1 \mathrm{~h}$ of incubation with Alexa Fluor 488-labeled goat anti-mouse lgG (Thermo Fisher Scientific, Poland) $(2.5 \mu \mathrm{g} / \mathrm{ml})$. Actin filaments were stained using phalloidin coupled with Alexa Fluor 633 (Thermo Fisher Scientific, Poland) $(0.2 \mathrm{U} / \mathrm{ml})$. Nuclear DNA was stained with DAPI (4',6-diamidino-2-phenylindole) (Sigma-Aldrich, Poland) $(0.1 \mu \mathrm{g} / \mathrm{ml})$. Immunostained cultures were mounted on glass slides in ProLong Gold antifade medium (Thermo Fisher Scientific, Poland). Fluorescent images were acquired under a Leica TCS SP5 II confocal microscope (Leica Microsystems GmbH, Mannheim, Germany) and a Zeiss LSM 710 confocal microscope (Carl Zeiss Microscopy $\mathrm{GmbH}$ ). Images were acquired using Leica Application Suite Advanced Fluorescence LAS AF v. 2.2.1 software (Leica Microsystems CMS GmbH) or ZEN 2012 SP1 software (Carl Zeiss Microscopy $\mathrm{GmbH}$ ) and were deconvolved with Huygens Essential package version 4.4 (Scientific Volume Imaging B.V., The Netherlands) and processed using ImageJ 1.47v (National Institutes of Health, Bethesda, MD, USA). At the time of the study, no antibodies specific to SARS-CoV-2 were available to us.

Pseudovirus production and transduction. 293T cells were seeded on 10-cm-diameter dishes, cultured for $24 \mathrm{~h}$ at $37^{\circ} \mathrm{C}$ with $5 \% \mathrm{CO}_{2}$, and transfected using polyethyleneimine (Sigma-Aldrich, Poland) with the lentiviral packaging plasmid (psPAX), the VSV-G envelope plasmid (pMD2G), or SARS-CoV-2 S glycoprotein (pCAGGS-SARS-CoV-2-S) and a third plasmid encoding firefly luciferase protein (pRRL luciferase). Cells were further cultured for $72 \mathrm{~h}$ at $37^{\circ} \mathrm{C}$ with $5 \% \mathrm{CO}_{2}$, and pseudoviruses were collected every $24 \mathrm{~h}$ and stored at $4^{\circ} \mathrm{C}$.

A549 ACE2+ cells were seeded in 48 -well plates, cultured for $24 \mathrm{~h}$ at $37^{\circ} \mathrm{C}$ with $5 \% \mathrm{CO}_{2}$, and transduced with pseudoviruses harboring VSV-G or S-SARS-CoV-2 proteins or lacking the fusion protein $(\Delta \mathrm{Env})$ in the presence of Polybrene (Sigma-Aldrich, Poland) $(4 \mu \mathrm{g} / \mathrm{ml})$ and HTCC-77 $(100 \mu \mathrm{g} / \mathrm{ml})$ or control PBS. After $4 \mathrm{~h}$ of incubation at $37^{\circ} \mathrm{C}$, unbound virions were removed by three washes with $1 \times \mathrm{PBS}$, and cells were further cultured for $72 \mathrm{~h}$ at $37^{\circ} \mathrm{C}$ with $5 \% \mathrm{CO}_{2}$. Cells were lysed in Bright-Glo luciferase assay buffer (Promega, Poland) and transferred onto white 96-well plates. Luminescence levels were measured on a Gemini EM microplate reader (Molecular Devices, United Kingdom).

Western blot analysis. Cells were trypsinized, centrifuged, and resuspended in radioimmunoprecipitation assay (RIPA) buffer (50 mM Tris, $150 \mathrm{mM} \mathrm{NaCl}, 1 \%$ Nonidet P-40, $0.5 \%$ sodium deoxycholate, $0.1 \%$ SDS, pH 7.5) followed by lysis for $30 \mathrm{~min}$ on ice. Subsequently, samples were centrifuged (10 min at $12,000 \times g)$, and the pelleted cell debris was discarded. The resulting supernatants were mixed with sample buffer (0.5 M Tris [pH 6.8], 10\% SDS, $50 \mathrm{mg} / \mathrm{ml}$ dithiothreitol [DTT]), boiled for $5 \mathrm{~min}$, cooled on ice, and separated on $10 \%$ polyacrylamide gels alongside dual-color Page Ruler prestained protein size markers (Thermo Fisher Scientific, Poland). The separated proteins were then transferred onto a Western $S$ polyvinylidene difluoride (PVDF) membrane (GE Healthcare, Poland) by wet blotting (Bio-Rad, Poland) for $1 \mathrm{~h}$ at $100 \mathrm{~V}$ in transfer buffer $\left(25 \mathrm{mM}\right.$ Tris, $192 \mathrm{mM}$ glycine, $20 \%$ methanol) at $4^{\circ} \mathrm{C}$. The membranes were then blocked by overnight incubation at $4^{\circ} \mathrm{C}$ in TBS-Tween (Tris-buffered saline-Tween) $(0.1 \%)$ buffer supplemented with 5\% skimmed milk (BioShop, Canada). Mouse anti-MERS-CoV N IgGs (Sino Biological, China) (1:1,000 dilution) and horseradish peroxidase (HRP)-labeled rabbit anti-mouse IgG (Dako, Denmark) $(65 \mathrm{ng} / \mathrm{ml})$ were used to detect MERS-CoV nucleocapsid protein. Mouse anti-SARS-CoV$2 \mathrm{~N}$ IgGs (Bioss Antibodies, USA) (1:1,000 dilution) and horseradish peroxidase-labeled rabbit anti-mouse IgG (Dako, Denmark) $(65 \mathrm{ng} / \mathrm{ml})$ were used to detect SARS-CoV-2 nucleocapsid protein. A rabbit antiglyceraldehyde-3-phosphate dehydrogenase (anti-GAPDH) antibody (Cell Signaling Technology, Poland) (1:5,000 dilution) and horseradish peroxidase-labeled goat anti-rabbit IgG (Sigma-Aldrich, Poland) $(0.35 \mu \mathrm{g} / \mathrm{ml})$ were used to detect the GAPDH in cell lysates. All antibodies were diluted in $1 \%$ skimmed milk-TBS-Tween (0.1\%). The signal was developed using Immobilon Western chemiluminescent HRP substrate (Millipore, USA).

Interaction between HTCC and SARS-CoV-2 spike protein. The fluorescence spectra of HTCC labeled with FITC ( $\mathrm{CHTCC}$-FITC $=0.5 \mu \mathrm{g} / \mathrm{ml}$ ) in water were measured in the absence and in the presence of various concentrations of SARS-CoV-2 and MERS-CoV spike protein S1 domains ranging from $0.05 \mu \mathrm{g} / \mathrm{ml}$ to $0.4 \mu \mathrm{g} / \mathrm{ml}$. Nuclear magnetic resonance (NMR) spectra were measured in deuterium oxide $\left(D_{2} O\right)$ using a Bruker Advance II 600-MHz spectrometer. Elemental analysis was performed using a Vario Micro CHNS elemental analyzer. UV-Vis absorption spectra were recorded using a Varian Cary 50 UV-Vis spectrometer in 1-cm-path-length quartz cuvettes. Fluorescence spectra of HTCC-FITC were measured at an excitation wavelength $\left(\lambda_{\mathrm{ex}}\right)=470 \mathrm{~nm}$ using a Hitachi F-7000 spectrofluorimeter at room temperature. Conductometric titrations were performed using an Elmetron CX-741 multifunction computer meter.

Statistical analysis. All the experiments were performed in triplicate, and the results are presented as means \pm standard deviations (SD). To determine the significance of the obtained results, Student's $t$ test was carried out. $P$ values of $<0.05$ were considered significant. 


\section{ACKNOWLEDGMENTS}

This work was supported by a subsidy from the Polish Ministry of Science and Higher Education for research on SARS-CoV-2, a grant from the National Science Center (UMO2017/27/B/NZ6/02488) to K.P., and EU-Horizon2020 ITN OrganoVir grant 812673.

The funders had no role in study design, data collection, and analysis, the decision to publish, or preparation of the manuscript.

The technology used as described in this article is owned by the Jagiellonian University (Krakow, Poland) and protected by patent no. WO2013172725A1 and associated documents.

A. Milewska, Y. Chi, A. Szczepanski, E. Barreto-Duran, M. Obloza, X. Guo, Y. Ge, J. Li, L. Cui, A. Dabrowska, and P. Botwina conducted the experiments. M. Ochman, M. Urlik, and S. R. Rodziewicz-Motowidlo provided materials and methods for the study. A. Milewska and K. Pyrc designed the study and experiments, analyzed the data, and wrote the manuscript. K. Liu, D. Liu, F. Zhu, M. Nowakowska, and K. Szczubialka analyzed the data. K. Pyrc supervised the study. All of us reviewed the manuscript and approved the submitted version. All of us agreed to be personally accountable for our own contributions and to ensure that questions related to the accuracy or integrity of any part of the work are appropriately investigated and resolved and that the resolution is documented in the literature.

We declare no competing financial interests.

\section{REFERENCES}

1. Knipe DM, Howley PM, Cohen Jl, Griffin DE, Lamb RA, Martin MA, Racaniello VR, Roizman B (ed). 2013. Fields virology, 6th ed. Lippincott Williams \& Wilkins, Philadelphia, PA.

2. Peiris JS, Yuen KY, Osterhaus AD, Stöhr K. 2003. The severe acute respiratory syndrome. N Engl J Med 349:2431-2441. https://doi.org/10.1056/ NEJMra032498.

3. de Groot RJ, Baker SC, Baric RS, Brown CS, Drosten C, Enjuanes L, Fouchier RA, Galiano M, Gorbalenya AE, Memish ZA, Perlman S, Poon LL, Snijder EJ, Stephens GM, Woo PC, Zaki AM, Zambon M, Ziebuhr J. 2013. Middle East respiratory syndrome coronavirus (MERS-CoV): announcement of the Coronavirus Study Group. J Virol 87:7790-7792. https://doi.org/10.1128/JVI .01244-13.

4. Zaki AM, van Boheemen S, Bestebroer TM, Osterhaus AD, Fouchier RA. 2012. Isolation of a novel coronavirus from a man with pneumonia in Saudi Arabia. N Engl J Med 367:1814-1820. https://doi.org/10.1056/ NEJMoa1211721.

5. van der Hoek L, Pyrc K, Jebbink MF, Vermeulen-Oost W, Berkhout RJ, Wolthers KC, Wertheim-van Dillen PM, Kaandorp J, Spaargaren J, Berkhout B. 2004. Identification of a new human coronavirus. Nat Med 10:368-373. https://doi.org/10.1038/nm1024.

6. van der Hoek L, Sure K, Ihorst G, Stang A, Pyrc K, Jebbink MF, Petersen G, Forster J, Berkhout B, Uberla K. 2005. Croup is associated with the novel coronavirus NL63. PLoS Med 2:e240. https://doi.org/10.1371/journal .pmed.0020240.

7. Zhu N, Zhang D, Wang W, Li X, Yang B, Song J, Zhao X, Huang B, Shi W, Lu R, Niu P, Zhan F, Ma X, Wang D, Xu W, Wu G, Gao GF, Tan W; China Novel Coronavirus Investigating and Research Team. 2020. A novel coronavirus from patients with pneumonia in China, 2019. N Engl J Med 382:727-733. https://doi.org/10.1056/NEJMoa2001017.

8. Yang J, Chen X, Deng X, Chen Z, Gong H, Yan H, Wu Q, Shi H, Lai S, Ajelli M, Viboud C, Yu PH. 2020. Disease burden and clinical severity of the first pandemic wave of COVID-19 in Wuhan, China. Nat Commun 11:5411. https://doi.org/10.1038/s41467-020-19238-2.

9. Andersen KG, Rambaut A, Lipkin WI, Holmes EC, Garry RF. 2020. The proximal origin of SARS-CoV-2. Nat Med 26:450-452. https://doi.org/10.1038/ s41591-020-0820-9.

10. Corman VM, Ithete NL, Richards LR, Schoeman MC, Preiser W, Drosten C, Drexler JF. 2014. Rooting the phylogenetic tree of Middle East respiratory syndrome coronavirus by characterization of a conspecific virus from an African bat. J Virol 88:11297-11303. https://doi.org/10.1128/JVI.01498-14.

11. Zhang Z, Shen L, Gu X. 2016. Evolutionary dynamics of MERS-CoV: potential recombination, positive selection and transmission. Sci Rep 6:25049. https://doi.org/10.1038/srep25049.
12. Lu G, Hu Y, Wang Q, Qi J, Gao F, Li Y, Zhang Y, Zhang W, Yuan Y, Bao J, Zhang B, Shi Y, Yan J, Gao GF. 2013. Molecular basis of binding between novel human coronavirus MERS-CoV and its receptor CD26. Nature 500:227-231. https://doi.org/10.1038/nature12328.

13. Raj VS, Mou H, Smits SL, Dekkers DH, Müller MA, Dijkman R, Muth $D$, Demmers JA, Zaki A, Fouchier RA, Thiel V, Drosten C, Rottier PJ, Osterhaus AD, Bosch BJ, Haagmans BL. 2013. Dipeptidyl peptidase 4 is a functional receptor for the emerging human coronavirus-EMC. Nature 495:251-254. https://doi.org/10.1038/nature12005.

14. Mackay IM, Arden KE. 2015. MERS coronavirus: diagnostics, epidemiology and transmission. Virol J 12:222. https://doi.org/10.1186/s12985-015-0439-5.

15. Milne-Price S, Miazgowicz KL, Munster VJ. 2014. The emergence of the Middle East respiratory syndrome coronavirus. Pathog Dis 71:121-136. https://doi.org/10.1111/2049-632X.12166.

16. Chan RW, Hemida MG, Kayali G, Chu DK, Poon LL, Alnaeem A, Ali MA, Tao KP, Ng HY, Chan MC, Guan Y, Nicholls JM, Peiris JS. 2014. Tropism and replication of Middle East respiratory syndrome coronavirus from dromedary camels in the human respiratory tract: an in-vitro and ex-vivo study. Lancet Respir Med 2:813-822. https://doi.org/10.1016/S2213-2600(14)70158-4.

17. Agostini ML, Andres EL, Sims AC, Graham RL, Sheahan TP, Lu X, Smith EC, Case JB, Feng JY, Jordan R, Ray AS, Cihlar T, Siegel D, Mackman RL, Clarke MO, Baric RS, Denison MR. 2018. Coronavirus susceptibility to the antiviral remdesivir (GS-5734) is mediated by the viral polymerase and the proofreading exoribonuclease. mBio 9:e00221-18. https://doi .org/10.1128/mBio.00221-18.

18. Agnihothram S, Yount BL, Donaldson EF, Huynh J, Menachery VD, Gralinski LE, Graham RL, Becker MM, Tomar S, Scobey TD, Osswald HL, Whitmore A, Gopal R, Ghosh AK, Mesecar A, Zambon M, Heise M, Denison MR, Baric RS. 2014. A mouse model for Betacoronavirus subgroup 2c using a bat coronavirus strain HKU5 variant. mBio 5:e00047-14. https:// doi.org/10.1128/mBio.00047-14.

19. Ratia K, Pegan S, Takayama J, Sleeman K, Coughlin M, Baliji S, Chaudhuri R, Fu W, Prabhakar BS, Johnson ME, Baker SC, Ghosh AK, Mesecar AD. 2008. A noncovalent class of papain-like protease/deubiquitinase inhibitors blocks SARS virus replication. Proc Natl Acad Sci U S A 105:16119-16124. https://doi.org/10.1073/pnas.0805240105.

20. Barnard DL, Day CW, Bailey K, Heiner M, Montgomery R, Lauridsen L, Winslow S, Hoopes J, Li JK, Lee J, Carson DA, Cottam HB, Sidwell RW. 2006. Enhancement of the infectivity of SARS-CoV in BALB/C mice by IMP dehydrogenase inhibitors, including ribavirin. Antiviral Res 71:53-63. https://doi.org/10.1016/j.antiviral.2006.03.001.

21. Cheng VC, Lau SK, Woo PC, Yuen KY. 2007. Severe acute respiratory 
syndrome coronavirus as an agent of emerging and reemerging infection. Clin Microbiol Rev 20:660-694. https://doi.org/10.1128/CMR.00023 $-07$.

22. Milewska A, Kaminski K, Ciejka J, Kosowicz K, Zeglen S, Wojarski J, Nowakowska M, Szczubiałka K, Pyrc K. 2016. HTCC: broad range inhibitor of coronavirus entry. PLoS One 11:e0156552. https://doi.org/10.1371/journal .pone. 0156552.

23. Milewska A, Ciejka J, Kaminski K, Karewicz A, Bielska D, Zeglen S, Karolak W, Nowakowska M, Potempa J, Bosch BJ, Pyrc K, Szczubialka K. 2013. Novel polymeric inhibitors of HCoV-NL63. Antiviral Res 97:112-121. https://doi.org/10.1016/j.antiviral.2012.11.006.

24. Kamil K, Aleksandra M, Maria N, Krzysztof P, Krzysztof S. June 2013. The use of chitosan polymer in the treatment and prevention of infections caused by coronaviruses. US patent 20150164938A1.

25. Yang TT, Wen BF, Liu K, Qin M, Gao YY, Ding DJ, Li WT, Zhang YX, Zhang WF. 2018. Cyclosporine A/porous quaternized chitosan microspheres as a novel pulmonary drug delivery system. Artif Cells Nanomed Biotechnol 46:552-564. https://doi.org/10.1080/21691401.2018.1463231.

26. Samworth CM, Degli Esposti M, Lenaz G. 1988. Quenching of the intrinsic tryptophan fluorescence of mitochondrial ubiquinol-cytochrome-c reductase by the binding of ubiquinone. Eur J Biochem 171:81-86. https://doi.org/10.1111/j .1432-1033.1988.tb13761.x.

27. Lakowicz JR. 1988. Principles of frequency-domain fluorescence spectroscopy and applications to cell membranes. Subcell Biochem 13:89-126. https://doi.org/10.1007/978-1-4613-9359-7_3.

28. Milewska A, Kula-Pacurar A, Wadas J, Suder A, Szczepanski A, Dabrowska A, Owczarek K, Ochman M, Stacel T, Rajfur Z, Labaj P, Branicki W, Pyrc K. 1988. Replication of SARS-CoV-2 in human respiratory epithelium. BioRxiv https://doi.org/10.1101/2020.03.20.999029.

29. Kühtreiber WM, Lanza RP, Chick WL (ed). 1999. Cell encapsulation technology and therapeutics. Springer Nature, Cham, Switzerland.

30. Ciejka J, Wolski K, Nowakowska M, Pyrc K, Szczubiałka K. 2017. Biopolymeric nano/microspheres for selective and reversible adsorption of coronaviruses. Mater Sci Eng C Mater Biol Appl 76:735-742. https://doi.org/10 .1016/j.msec.2017.03.047.

31. Milewska A, Zarebski M, Nowak P, Stozek K, Potempa J, Pyrc K. 2014. Human coronavirus NL63 utilizes heparan sulfate proteoglycans for attachment to target cells. J Virol 88:13221-13230. https://doi.org/10 .1128/JVI.02078-14. 